\title{
Os Kollegnachschriften de Nietzsche. Considerações sobre uma lacuna das obras completas*
}

\author{
Eduardo Nasser**
}

Resumo: Não obstante as reconhecidas virtudes da edição crítica - Kritische Gesamtausgabe (KGW) -, há o entendimento de que as duas primeiras seções dessa edição, que abrangem os escritos de juventude e filológicos, possuem lacunas. Uma dessas lacunas, contida na seção I, decorre da problemática decisão de não incorporar, em sua totalidade, os registros de aulas realizados por Nietzsche no período universitário, os Kollegnachschriften, valiosos tanto para estudos genéticos e de contextualização, como também para estudos de fontes. Muito embora o surgimento da Digitale Faksimile Gesamtausgabe (DFGA) tenha dado início a um reparo dessa falha ao publicar todos os cadernos universitários de Nietzsche em formato fac-símile, os problemas de acesso a esses documentos não foram ainda completamente superados.

Palavras-chave: Filologia, Fontes, Espólio, Manuscritos.

\footnotetext{
* Agradeço imensamente a Daniel Weißbrodt pelo suporte com o trabalho de transcrições.

** Albert-Ludwigs-Universität Freiburg, Freiburg, Alemanha.

ORCID https://orcid.org/0000-0002-8415-7149

Correio eletrônico: eduardo.nasser@philosophie.uni-freiburg.de
} 
Nasser, E.

\section{Juvenilia e Philologica}

Após os infames episódios de adulterações envolvendo as primeiras edições das obras completas de Nietzsche, que culminam na fabricação da obra apócrifa $A$ vontade de potência, deparamos, em meados do século passado, com tentativas de recuperação do espólio literário do filósofo. A esse respeito, convém mencionar a edição histórico-crítica (BAW), as edições elaboradas por Karl Schlechta e Erich Podach, e, enfim, a edição crítica organizada por Giorgio Colli e Mazzino Montinari, Kritische Gesamtausgabe (KGW). Em nossa atualidade, esta última é amplamente reconhecida pelos especialistas como a edição mais criteriosa e, no limite, como aquela que verdadeiramente impulsionou um movimento de inflexão no âmbito dos estudos nietzschianos ${ }^{1}$.

A edição crítica traz uma grande quantidade de melhorias: do lado editorial, recuperação de documentos corrompidos, correções de transcrições e datações inadequadas, e divulgação de material inédito; do lado metodológico, estabelecimento de um critério cientificamente mais adequado de organização do espólio literário, cronológico e histórico ao invés de temático ${ }^{2}$. Contudo, esse empreendimento retificador não foi originariamente dispensado aos escritos de juventude - Juvenilia - e filológicos - Philologica .

É importante observar que esse material enfrenta desde muito cedo uma recepção relutante, visto que não era considerado parte da produção que encerrava o pensamento genuíno de Nietzsche. É de supor que na preparação da primeira edição finalizada das obras completas, Grossoktavausgabe (GOA), havia sido cogitada a possibilidade de integrar uma parcela considerável dos textos do período estudantil até os anos da docência. Nos primeiros esboços do projeto dessa edição, manifestamente abrangentes, concebidos por Heinrich Köselitz, temos a seção A, que deveria incluir os textos

1 Tome-se como exemplo o papel decisivo da edição Colli-Montinari para o estabelecimento dos estudos acadêmicos de Nietzsche no Brasil. Cf. Marton, 2013, pp. 107 - 118.

2 Cf. Fornari, 2019, pp. 129 - 151.

90 | Cad. Nietzsche, Guarulhos/Porto Seguro, v.42, n.1, p. 89-110, janeiro/abril, 2021. 
Os Kollegnachschriften de Nietzsche. Considerações sobre uma lacuna...

publicados, ou que estavam no mesmo patamar destes, a seção B, que deveria abarcar o espólio filosófico, a seção C, Philologica, e a seção D, Collegia ${ }^{3}$. Porém, quando da publicação, os textos filológicos e dos cursos oferecidos em Basel são lançados entre 1910-13 de forma incompleta numa única seção (terceira seção, Philologica), volumes XVII-XIX, afora serem suprimidos da versão diminuída da GOA, publicada em paralelo, a Kleinoktavausgabe ${ }^{4}$. Sobre a Philologica, Erwin Rohde, convidado por Elisabeth para ser o organizador dessa seção, já havia compartilhado impressões negativas acerca da possibilidade de publicar os manuscritos dos cursos e o espólio filológico de Nietzsche. Apesar de constatar alguma utilidade em manuscritos de cursos, como Os filósofos préplatônicos e a Enciclopédia, Rohde julga que o melhor seria optar pela não divulgação. Sem contar que se tratava de um material que não foi elaborado para leitura, e que já tinha se tornado obsoleto defronte os estudos eruditos, essas notas possuíam raras observações verdadeiramente originais. No seu modo de ver, a parte do projeto editorial voltada para os escritos filológicos só teria alguma pertinência se limitada à reunião de artigos previamente publicados por Nietzsche em periódicos especializados de filologia ${ }^{5}$. Esse cenário pouco promissor, que precede a preparação dessa seção, pode ajudar a entender por que Holzer - o organizador que, enfim, assume a Philologica - manifesta certo receio com a publicação dos textos inéditos, em particular os manuscritos dos cursos, priorizando a inclusão de escritos que possuíssem algum tipo de relação com obras e ensaios já conhecidos de Nietzsche. Holzer alega, por exemplo, que Introdução à tragédia de Sófocles ajudaria a compreender $O$

3 Cf. Carta de Heinrich Köselitz a Franz Overbeck, dia 12 de abril de 1894. In: Hoffmann, Peter, Salfinger, 1998, p. 403. Posteriormente, Elisabeth afirmará que o autor do projeto originário das seções teria sido Erwin Rohde. Como já mostrou Hoffman, trata-se de um testemunho pouco confiável. Cf. Hoffmann, 1991, p. 155.

4 Cf. Hoffmann, 1991, p. 84. Hoffmann, 1993, p. 29.

5 Cf. Carta de Erwin Rohde a Elisabeth Nietzsche, dia 16 de junho de 1894. In: Däuble, 1976, pp. 348 -349. Carta de Erwin Rohde a Franz Overbeck, dia 27 de dezembro de 1894. In: Patzer, 1990, p. 168. 
Nasser, E.

nascimento da tragédia; que a Enciclopédia da fllologia clássica serve de fio condutor para Sobre o futuro de nossos estabelecimentos de formação e a segunda Consideração extemporânea ${ }^{6}$.

Poder-se-ia crer que os escritos colocados em segundo plano recebem um acolhimento mais apropriado nas edições de obras completas que sucedem a GOA. Na edição Musarion nós encontramos, pela primeira vez, a publicação, malgrado parcial, dos escritos de juventude ${ }^{7}$. Na edição histórico-crítica (BAW), deparamos com uma realização ainda mais robusta. Apesar dessa edição ter sido interrompida pela guerra - dos 40 volumes previstos, somente 5 são lançados -, os organizadores almejam trazer a público tudo que Nietzsche produz entre os anos de 1854-69, dos escritos de juventude até os textos dos primeiros tempos de Basel. Conforme Hans Joachim Mette, um dos organizadores, pretendia-se "publicar tudo, sem exceção", incluindo esboços, planos para livros, citações completas, etc. (Mette, 1994a, p. IX). Com efeito, desde seu nascimento, em 1922, o projeto da edição histórico-crítica se destacava pela iniciativa de publicar manuscritos ainda não transcritos ${ }^{8}$.

Essa edição, em particular, foi bem recebida no campo de estudos especializados. Esse foi um dos motivos que fez com que Montinari priorizasse, em seu trabalho editorial restaurador, a produção tardia de Nietzsche, em especial os póstumos da década de 1880 envoltos na polêmica gerada por A vontade de potência. Em suas palavras, "tínhamos um texto confiável para os escritos de juventude e para a Philologica, disponíveis nas obras completas histórico-crítica (Bde. I-V, 1933/40), portanto para os escritos de 1854 até a primaveraverão de 1869 (os primeiros tempos de Basel)". Montinari estava convencido de que o material contemplado na edição BAW havia sido submetido a um tratamento meticuloso, restando tão somente

6 Cf. Holzer, 1910, p. XIII e XIV.

7 Cf. Montinari, 1982, p. 12.

8 Cf. Hoffmann, 1991, p. 96.

92 | Cad. Nietzsche, Guarulhos/Porto Seguro, v.42, n.1, p. 89-110, janeiro/abril, 2021. 
Os Kollegnachschriften de Nietzsche. Considerações sobre uma lacuna...

o "autêntico espólio filosófico" que começa com a "preparação de O nascimento da tragédia" (Montinari, 1982, p. 19). Não se trata, decerto, de um assentimento irrestrito aos resultados conquistados pela edição BAW. Se assim fosse, Montinari não manifestaria, numa troca de carta com Colli, certa apreensão com a maneira como ambos conduziam a questão dos escritos de juventude ${ }^{9}$. Porém, estava se assumindo que o trabalho crítico e editorial com esses grupos de documentos poderia ser adiado sem grandes prejuízos.

Infelizmente, a confiança depositada por Montinari na edição BAW terminou por se revelar injustificada. Não obstante o diligente trabalho de transcrições, a edição ainda partilha de certos princípios da GOA, lançando mão de uma cronologia imprecisa, indulgente com frágeis critérios temáticos de organização - como a divisão entre escritos filológicos e filosóficos ${ }^{10}$. Além do mais, a edição exclui uma grande quantidade de anotações, como as notas da época escolar em Naumburg, poemas, traduções, etc. ${ }^{11}$

Diante desse cenário embaraçoso que circunda os escritos de juventude e filológicos, a finalização das seções I e II da edição KGW, entre as décadas de 1980 e 1990, foi cercada por muita expectativa - as seções que Montinari tinha deixado por fazer. Na seção I, temos acesso a uma massa de material inédito arranjada cronologicamente boa parte do que havia sido suprimido da edição BAW -, começando pela primeira anotação de Nietzsche, feita em 1853, estendendo-se até 1869, quando se inicia, então, a seção III. A seção II, por sua vez, contém os escritos filológicos, os artigos publicados por Nietzsche em periódicos, bem como os manuscritos dos seus cursos, incluindo alguns inéditos, como o curso sobre gramática latina. Todavia, essas publicações não foram recebidas com muito entusiasmo, ao contrário

9 Montinari temia que questões sobre o Jugendwerke pudessem ser colocadas quando da apresentação que ele e Colli realizariam da nova edição no Colóquio de Royaumont. Cf. Carta de Mazzino Montinari a Giorgio Colli, dia 10 de maio de 1964. In: Campioni, 1989, p. LIII.

10 Cf. Schlechta, 1994, p. 438 - 464.

11 Cf. Figl, 1994, p. 161 - 168. Figl, 1995, pp. 317 - 318. Figl, 1999, p. VII e VIII.

Cad. Nietzsche, Guarulhos/Porto Seguro, v.42, n.1, p. 89-110, janeiro/abril, 2021. | 93 
Nasser, E.

do que se poderia imaginar. A seção II enfrenta uma recepção negativa em virtude da ausência de aparato crítico, transcrições imperfeitas, datações equivocadas e decisões editoriais temerárias ${ }^{12}$. Sobre a seção I, as críticas são seguramente menos severas e abundantes; mas elas existem. E o principal problema constatado foi a não publicação dos cadernos de notas de Nietzsche enquanto estudante.

\section{A lacuna da seção I da KGW}

Importante destacar, primeiramente, que Johann Figl, responsável pela organização dos volumes 2 - 4 da seção I da KGW, é possivelmente o maior defensor da relevância acadêmica dos cadernos estudantis de Nietzsche. Referindo-se mais diretamente aos registros de aulas do período universitário, os Kollegnachschriften (KN), Figl alega que essas notas documentam o primeiro encontro de Nietzsche com a filosofia, com as principais tendências da filologia, com interpretações sobre outras culturas, etc. Ademais, ele também nos dirá que, vistas num quadro mais geral, essas notas serviriam de instrumento para traçar a geração de ideias que serão mobilizadas pelo pensamento nietzschiano amadurecido $^{13}$. Essa seria também a impressão de Montinari. Figl compartilha preciosas recordações de conversas em que Montinari ressalta a importância desse material para estudos de cunho biográfico e de fontes; a seu ver, seria essencial "para a compreensão da gênese do pensamento de Nietzsche" (Figl, 1989, p. 456).

"Pelas razões mencionadas", assevera Figl, "é aconselhável publicar as notas indicadas da maneira mais completa possível" (Figl, 1989, p. 456), uma tarefa que ele mesmo se dispõe a executar. É verdade que Mette já havia levado a cabo uma excelente e acurada catalogação dos cadernos escolares e universitários de Nietzsche siglas Mp e C -, então designados como parte do espólio no sentido estrito. Somos informados sobre os tipos de cadernos, a forma como se

12 Cf. Porter, 2000, pp. 409 - 431. Santini, 2012, p. 270. Arenas-Dolz, 2019, p. 113 - 114.

13 Cf. Figl, 1988, p. 501. Figl, 1989, p. 456. Figl, 2007, pp. $160-161$.

94 | Cad. Nietzsche, Guarulhos/Porto Seguro, v.42, n.1, p. 89-110, janeiro/abril, 2021. 
Os Kollegnachschriften de Nietzsche. Considerações sobre uma lacuna...

localizavam no Nietzsche-Archiv, e o conteúdo correspondente a cada um $^{14}$. Porém, o conteúdo mesmo não é incorporado à edição BAW. Nesse sentido, Figl deve ser tratado como o verdadeiro idealizador de um projeto editorial claramente dedicado aos KN; ele foi o responsável pelas primeiras reproduções de trechos dessas anotações em artigos e livros, assim como pela composição de um projeto de publicação desse material no contexto da edição KGW. Poder-se-ia então esperar uma correção definitiva da lacuna deixada pela edição BAW; mas não é o que realmente acontece. Segundo Figl, a proposta seria a de lançar, na forma de apêndice, somente uma parcela dos KN, qual seja, as notas com teor não filológico, que correspondem à menor parte dos manuscritos (cerca de 150 folhas de manuscritos, enquanto os KN filológicos possuem aproximadamente 1100 folhas). No seu entender, seria aqui que encontraríamos os elementos mais significativos para compreendermos a formação de Nietzsche ${ }^{15}$.

Sem contar que esse apêndice não foi lançado passados mais de vinte anos do prefácio da seção I - o que atualmente é visto como uma falha da edição $0^{16}-$, o projeto delineado continua se servindo de contestáveis expedientes metodológicos, justamente aqueles que Figl censura quando se dirige às edições precedentes das obras completas: seleção e critério temático de ordenação dos escritos. Como bem apontou Christian Benne, além da decisão de Figl atribuir uma menor importância aos cadernos filológicos, ela ainda repercute aquela "desastrosa e arbitrária separação do Nietzsche filológico do filosófico" (Benne, 2005, p. 17) ${ }^{17}$. A objeção de Benne se justifica por meio de

14 Cf. Mette, 1932, pp. 24 - 30. Mette, 1994b, pp. LIII - LIX.

15 Cf. Figl, 1999, p. IX.

16 Cf. Colsen, 2020, p. 100.

17 Posição semelhante pode ser encontrada em Colsen. Cf. Colsen, 2020, p. 117. Numa curta resposta à crítica de Benne, Figl ressalta que não foi bem compreendido, pois ele prossegue comprometido com o projeto de publicação de "todas essas anotações", ainda que isso não signifique necessariamente publicá-las "como livro" (Figl, 2007, pp. 160 - 161). Figl parece sugerir que essas publicações ocorreriam de modo esporádico em suas próprias produções acadêmicas, uma solução que, a meu ver, continua sendo pouco eficaz.

Cad. Nietzsche, Guarulhos/Porto Seguro, v.42, n.1, p. 89-110, janeiro/abril, 2021.| 95 
Nasser, E.

uma simples consulta dos KN supostamente filológicos. Por exemplo, nas notas feitas por Nietzsche do curso Institutiones grammaticae linguae latinae (SS 1865), oferecido por Ritschl em Bonn, encontramos reflexões claramente filosóficas acerca da linguagem - como o papel da lógica e da imaginação no desenvolvimento da linguagem -, bem como interlocuções com nomes da história da filosofia, como Kant e W. Humboldt ${ }^{18}$. Já em notas do curso oferecido por Curtius em Leipzig, Griechische Grammatik (WS 1866/67), constatamos a existência de uma valiosa tematização do tratamento dado pela filosofia grega à linguagem, com menções a Protágoras, Demócrito, Platão, Aristóteles, etc., representantes do primeiro período da história da gramática $^{19}$. Esses exemplos colocam em evidência o traço fortemente interdisciplinar dos KN - em particular a constante presença de discussões filosóficas -, característica que inviabiliza um projeto editorial apoiado em divisões temáticas. Se os KN não filológicos são indispensáveis para conhecer a trajetória formativa de Nietzsche, como afirma Figl, então não se pode abrir mão, de qualquer modo, da publicação integral dos cadernos correspondentes.

Mas há um fator ainda mais inquietante para se lamentar a ausência dos KN na seção I da KGW, como mostrarei a seguir.

\section{Estatuto dos Kollegnachschriften}

Para Figl, os KN devem ser consultados com a finalidade de determinar o pano de fundo espiritual e científico que contornava Nietzsche. Essas anotações contribuiriam para uma tarefa de contextualização, por meio da qual se faria possível, por comparação, "reconhecer o autêntico Nietzsche e a originalidade de seu pensamento" (Figl, 1989, p. 456). Contudo, Figl adverte que não está reivindicando o estabelecimento de uma conexão causal entre contexto e pensamento. Como ele nos diz em apreciações metodológicas a respeito de seu

18 Cf. GSA 71/43, folhas $3-4$.

19 Cf. GSA 71/50, folhas $5-7$.

96 | Cad. Nietzsche, Guarulhos/Porto Seguro, v.42, n.1, p. 89-110, janeiro/abril, 2021. 
Os Kollegnachschriften de Nietzsche. Considerações sobre uma lacuna...

trabalho com diferentes tipos de documentos literários de Nietzsche, incluindo os KN, dificilmente alguém negaria inteiramente a relação entre o contexto biográfico de um autor e o seu pensamento; mas o pensamento pode ser investigado sem a vida e vice-versa. Assim, ele deixa claro que o seu interesse não é movido tanto pela "derivação' das ideias de Nietzsche de determinadas fontes, mas na documentação do encontro de Nietzsche com intuições concretas, na verificação do conhecimento de determinadas interpretações" (Figl, 1984, p. 45). Com essa declaração, Figl anula a pretensão de localizar uma relação direta entre o conteúdo dos KN com a produção própria de Nietzsche. Os KN nada mais seriam do que acessórios de contextualização.

À diferença de Figl, eu procurarei mostrar que essas notas podem também possuir estatuto de fontes para os escritos nietzschianos, sobretudo para a composição dos textos dos cursos de Basel.

Comecemos observando que Nietzsche parecia ter pouca estima pelos seus cadernos universitários. Em sua retrospectiva do período leipzigiano, ele revela que não possuía um único "caderno completo dos cursos, mas somente lastimáveis fragmentos". Tratar-se-ia de um reflexo de seu desinteresse pelo conteúdo transmitido em aulas, haja vista que ele devotava a atenção, prioritariamente, para questões de cunho metodológico e pedagógico, em suma, o seu interesse era "aprender como se é professor" (Nachlass/FP, 60[1], KGW I, 4. 512). Essa passagem foi usada pelos biógrafos como um testemunho da falta de entusiasmo de Nietzsche para com os temas das disciplinas universitárias em Bonn e Leipzig e, consequentemente, como prova da irrelevância científica dos $\mathrm{KN}^{20}$.

Contudo, essa parece ser uma conclusão precipitada. Em primeiro lugar, o nível de envolvimento de Nietzsche enquanto estudante com as atividades universitárias oscila durantes os anos em que esteve em Bonn e Leipzig. O epistolário oferece um suporte valioso para essa alegação. Assim como temos cartas de Nietzsche

20 Cf. Ross, 1997/98, pp. 109 - 110. Janz, 1981, p. 143 e 178.

Cad. Nietzsche, Guarulhos/Porto Seguro, v.42, n.1, p. 89-110, janeiro/abril, 2021. | 97 
Nasser, E.

com queixas dirigidas aos cursos, às instituições que frequenta e, no limite, à filologia ${ }^{21}$, em outras encontramos declarações mais favoráveis nas quais ele exalta os conteúdos transmitidos em aulas e as competências dos seus professores, em particular Ritsch ${ }^{22}$. Decerto o ano de 1868 pode ser encarado como marco de uma mudança de temperamento que conduz a um maior afastamento, pois Nietzsche já não se via mais como aluno ${ }^{23}$. Contudo, esse episódio não confirma forçosamente um até então latente sentimento de decepção com a sua trajetória estudantil no ensino superior.

Em segundo lugar, o estado fragmentado não encerra os cadernos universitários em sua totalidade e tampouco é necessariamente indício de pouca assiduidade. Sobre esse último ponto, Metterhausen chama a atenção para o grande interesse de Nietzsche em empreender registros cuidadosos das aulas, comprometendo-se, nos dois primeiros semestres em Bonn, com correções e aperfeiçoamentos sistemáticos das anotações após as aulas, um projeto pessoal posteriormente prejudicado em virtude da grande quantidade de obrigações ${ }^{24}$. Essa parece ser uma afirmação inteiramente legítima. Tomemos uma carta que vai ao seu encontro, enviada por um colega de Leipzig no início de 1868, Reinhold Dressler, na qual ele solicita a Nietzsche a devolução de cadernos com anotações dos cursos de Ritschl e Curtius, muito provavelmente usados para realizar a tarefa retificadora ${ }^{25}$. Por fim, não são também

21 Cf. Carta a Hermann Mushacke, 30 de agosto de 1865, KSB 2. 80 - 81. Carta a Hermann Mushacke, 27 de abril de 1866, KSB 2. 127 - 129. Carta a Erwin Rohde, 6 de junho de 1868, KSB 2. 287.

22 Cf. Carta a Franziska e Elisabeth Nietzsche, 10 - 17 de novembro de 1864, KSB 2. 18. Carta a Franziska Nietzsche, 7 e 9 de dezembro de 1864, KSB 2. 22. Carta a Franziska e Elisabeth Nietzsche, 10 de maio de 1865, KSB 2. 52 - 53. Carta a Franziska e Elisabeth Nietzsche, 31 de outubro de 1866, KSB 2. 176. Carta a Hermann Mushacke, novembro de 1866, KSB 2. 180 - 181. Carta a Paul Deussen, dia 4 de abril de 1867, KSB 2. 205. Carta a Hermann Mushacke, 20 de abril de 1867, KSB 2. 214. Carta a Friedrich Ritschl, dia 29 de dezembro de 1867, KSB 2. 245.

23 Cf. Carta a Paul Deussen, segunda metade de outubro, KSB 2. 329. Carta a Erwin Rhode, 27 de outubro de 1868, KSB 2. 330. Carta a Gustav Krug, 16 de novembro de 1868, KSB 2. 343.

24. Cf. Metterhausen, 1942, p. 21.

25 Cf. Carta de Reinhold Dressler a Nietzsche, 10 de maio de 1868, KGB I, 3. 255.

98 | Cad. Nietzsche, Guarulhos/Porto Seguro, v.42, n.1, p. 89-110, janeiro/abril, 2021. 
Os Kollegnachschriften de Nietzsche. Considerações sobre uma lacuna...

todos os KN que apresentam sinais de incompletude ${ }^{26}$. Como bem salienta Hoyer, "as anotações dos cursos de Curtius e o caderno das sessões sobre Ésquilo e sobre gramática latina do semestre de inverno de 66/67 são abrangentes e pouco fragmentadas" (Hoyer, 2002, p. 175).

Embora não seja um desafio verdadeiramente penoso demonstrar a seriedade com que Nietzsche tratou os seus cadernos durante a época em que foi estudante universitário, o mesmo não pode ser dito dos momentos subsequentes de seu itinerário intelectual. Afinal, tudo faz crer que, no início de 1869, quando Nietzsche segue para Basel a fim de iniciar a sua carreira na docência, todos os documentos do período universitário e do serviço militar - além dos cadernos, incluem-se folhas soltas com anotações -, foram deixados em Naumburg, onde já estavam reunidos os cadernos escolares, e jamais foram relidos ${ }^{27}$. Porém, também existem indícios, ainda que menos perceptíveis, de que o destino dos cadernos universitários não se limita, a partir de 1869, a ampliar a Memorabilia nietzschiana e a satisfazer o ímpeto colecionista de Elisabeth. Esses vestígios são o de que Nietzsche se serviu desse material para elaborar parte dos seus cursos em Basel. Essa é uma antiga suspeita dos estudiosos. Ross, por exemplo, indaga se os manuscritos do curso sobre lírica grega não poderiam ter sido previamente redigidos enquanto anotações de aulas de Curtius ${ }^{28}$. Hoyer, por sua vez, enfatiza a similitude entre os cursos oferecidos por Nietzsche em Basel com o conteúdo dos KN; suas aulas sobre gramática latina e epigrafia latina evocam cursos de Ritschl, enquanto aquelas sobre lírica grega, enciclopédia e literatura grega evocam cursos de Curtius ${ }^{29}$.

É importante ter alguma cautela antes de se assumir que seria possível encontrar nos manuscritos dos cursos de Basel cópias completas dos KN, como parece sugerir Ross. Pois as paráfrases

26 Uma lista dos KN incompletos pode ser encontrada em: Gerratana e Müller-Buck, 1993, pp. 357 - 358. 27 Cf. Mette, 1932, pp. $24-25$.

28 Cf. Ross, 1997/98, p. 206.

29 Cf. Hoyer, 2002, p. 198.

Cad. Nietzsche, Guarulhos/Porto Seguro, v.42, n.1, p. 89-110, janeiro/abril, 2021.| 99 
Nasser, E.

contidas nos textos dos cursos costumam ser produzidas de uma forma bastante peculiar.

Lembremo-nos de que os textos de aula não gozam de boa reputação justamente em razão das frequentes identificações de paráfrases ou citações literais, acompanhadas pelo reconhecimento de poucas inovações técnicas e conceituais. Tome-se como exemplo a admissão feita por Nietzsche de que ele se servia de Ritschl para montar os seus seminários na Universidade ${ }^{30}$. Um depoimento como esse respalda a opinião de que o interesse de Nietzsche pela vida universitária, agora como docente e pesquisador, era mínimo, e que a leitura dos manuscritos dos cursos por ele produzidos deve ser desprovida de expectativas elevadas ${ }^{31}$. Porém, trata-se novamente de uma conclusão apressada. Assim como vimos no caso do período estudantil, Nietzsche manifesta sentimentos ambíguos sobre a sua vida enquanto docente em Basel. Ao longo do período da docência ele se mostra muito regularmente esgotado e entediado com as incumbências profissionais, aventando a possibilidade de abandonar o trabalho para ir a Bayreuth ou se instalar no convento para espíritos livres que ansiava erigir em Sorrento ${ }^{32}$. Mas ao mesmo tempo ele relata satisfação com a vida na Universidade e com os cursos que oferece ${ }^{33}$. É também esse Nietzsche perseverante e motivado que ministra os cursos em Basel, não só se esforçando por oferecer contribuições

30 Cf. Carta a Friedrich Ritschl, 10 de maio de 1869, KSB 3. 7.

31 Cf. Ross, 1997/98, pp. 206 - 207.

32 Cf. Carta a Paul Deussen, julho de 1869, KSB 3. 21. Carta a Gustav Krug, 17 de novembro de 1869, KSB 3. 74. Carta a Cosima von Bülow, 19 de junho de 1870, KSB 3. 125. Carta a Erwin Rohde, 15 de dezembro de 1870, KSB 3. 165 - 166. Carta a Wilhelm Vischer(-Bilfinger), provavelmente janeiro de 1871, KSB 3. 174 - 178. Carta a Franziska e Elisabeth Nietzsche, provavelmente 21 de janeiro de 1871, KSB 3. 178. Carta a Erwin Rohde, 29 de março de 1871, KSB 3. 191.

33 Cf. Carta a Erwin Rhode, meio de julho de 1869, KSB 3. 27. Carta a Erwin Rhode, 3 de setembro de 1869, KSB 3. 53. Carta a Elisabeth Nietzsche, 25 de setembro de 1869, KSB 3. 54. Carta a Wilhelmine Oehler, 4 de novembro de 1870, KSB 3. 153. Carta a Erwin Rohde, 11 de junho de 1872.

100 | Cad. Nietzsche, Guarulhos/Porto Seguro, v.42, n.1, p. 89-110, janeiro/abril, 2021. 
originais para a sua área de atuação ${ }^{34}$, como compondo os textos das aulas com esmero ${ }^{35}$. Esse zelo repercute no modo como ele lida com as fontes quando da produção dos textos dos cursos, pois antes de justapor mecanicamente excertos, Nietzsche realiza recortes e colagens estratégicas ${ }^{36}$. É tendo em vista essa idiossincrasia que se deve compreender o uso realizado dos KN nesse contexto, porquanto, em geral, eles são incorporados na forma de curtos recortes, muitas vezes sumarizados, e oportunamente distribuídos nos textos de aulas. Como exemplo, eu trago abaixo um trecho localizado no curso sobre gramática latina.

A linguagem é uma planta com um impulso interno de formação (Bildungstriebe). E ainda assim não se deve desvalorizar a formação através do espírito humano consciente, determinação teorética por doutrina, ao menos no latim. Ao contrário dos gregos, as investigações gramaticais só emergem quando a língua está finalizada. Com os latinos, com os poetas mais antigos, a reflexão é ativa (Vorlesungen über lateinische Grammatik, KGW II, 2.191).

$\mathrm{O}$ trecho citado evoca um esquema contido nos $\mathrm{KN}$ dos cursos de Ritschl, geralmente situado no início. Segue uma passagem extraída das notas do curso Institutiones grammaticae linguae latinae.

1. A lei do desenvolvimento físico descoberta principalmente por Wilh. v. Humboldt. A linguagem chega a uma vida independente, é uma planta, mas apenas relativamente independente.

34 Segundo Santini, "qualquer tentativa de abordagem dos textos dos cursos deve primeiro ser entendida como pura pesquisa de fonte" (Santini, 2012, p. 272). Mas isso não significa que tudo se reduza a estudo de fontes. Como diz Bornmann, que segue uma linha de leitura não muito distante de Santini, nem tudo nos manuscritos dos cursos é compilação. Cf. Bornmann, 1994, pp. 70 - 80.

$35 \mathrm{Em}$ 1869, Nietzsche revela que o modo como prepara as aulas consome suas energias, impedindo-o de produzir publicações muito extensas. Cf. Carta a Erwin Rohde, 16 de outubro de 1869, KSB 3. 65.

36 Como bem observam Most e Fries, Nietzsche cria um "tipo de mosaico a partir de diferentes pequenos fragmentos de texto" (Most e Fries, 1994, p. 33). Essa idiossincrasia pode ser comprovada, por exemplo, na elaboração da seção sobre a filologia francesa contida no curso Enciclopédia da filologia clássica. Cf. Nasser, 2020, pp. 301 -305. Nasser, 2020, pp. 306 -309. Nasser, 2020, pp. 310 - 313. 
Nasser, E.

2. A linguagem é ainda mais. A matéria da linguagem é determinada pelo espírito do homem, sobretudo pelo pensamento lógico. Este princípio encontrou o seu principal representante na escola germânica essencialmente através da filosofia kantiana. Mas a imaginação contribuiu tanto quanto para isso, especialmente a poesia, o sentido estético. $\mathrm{O}$ terceiro fator de natureza subordinada é a determinação teórica pela doutrina reflexiva (GSA 71/43, folhas 3-4) ${ }^{37}$.

É preciso reparar que, na citação do curso sobre gramática latina, Nietzsche suprime as referências feitas a Humboldt e Kant, não separa claramente os pontos e, enfim, sobrepõe os últimos dois numa mesma sentença. Ainda assim, através de uma confrontação com os KN, torna-se evidente que estamos diante de uma paráfrase dos três fatores para a formação da linguagem de Ritschl ${ }^{38}$. Em vista disso, é de supor que Nietzsche consultou algum dos seus cadernos universitários quando da preparação do texto do curso.

\section{Digitale Faksimile Gesamtausgabe (DFGA): avanços e novos desafios}

Um primeiro passo importante para preencher a lacuna da seção I da KGW foi dado no contexto do projeto Nietzsche Source, dirigido por Paolo D'Iorio. Em sua orientação editorial de trabalho, encontramos o projeto Digitale Faksimile Gesamtausgabe (DFGA), uma vigorosa iniciativa cujo principal propósito é oferecer um quadro evolutivo dos documentos que compõem o legado textual de Nietzsche ${ }^{39}$. Na DFGA, tipos variados de manuscritos são reproduzidos no formato facsímile, incluindo os KN. Com a edição fac-símile, pode-se dizer que os cadernos universitários de Nietzsche são publicados pela primeira

37 Esquema similar pode ser localizado nas anotações dos cursos Einleitung und Anleitung zur lateinischen Grammatik, Historische Grammatik e Lateinische Grammatik. Cf. GSA 71/53, folha 7. GSA 71/54, folhas $2-3$. GSA 71/55, folhas $3-4$.

38 Cf. Ribbeck, 1879, p. 271.

39 Cf. D’Iorio, 2017, pp. $190-204$.

102 | Cad. Nietzsche, Guarulhos/Porto Seguro, v.42, n.1, p. 89-110, janeiro/abril, 2021. 
vez. Todos eles encontram-se online para consulta e download na aba "Notebooks" do site e estão organizados em conformidade com a classificação de Mette ${ }^{40}$.

Porém, há ainda uma série de dificuldades que devem ser levadas em consideração.

(i) As irregularidades gráficas da caligrafia de Nietzsche nesses cadernos. Mesmo que não se trate do cenário dramático da caligrafia dos anos 1880, quando o próprio Nietzsche declara ser impraticável ler o que escreve sem recorrer à adivinhação ${ }^{41}$, é inegável que estamos lidando com um material de difícil acesso ${ }^{42}$. Em geral, Nietzsche usa na época um tipo de caligrafia trivial, Kurrentschrift, que não impõe, a princípio, grandes dificuldades de decifração. No entanto, a sua caligrafia sofre substanciais variações nos seus cadernos universitários. Quando a escrita é lenta, as letras inclinam-se de maneira uniforme, ligeiramente para a direita; todas as letras são escritas aqui de forma legível. Porém, quando a escrita é rápida, as letras tendem para a vertical, tornando-se mais irregulares e desarmoniosas; nesse caso, é também recorrente o aumento de espaços entre as letras de uma mesma palavra. Essas são alterações que intensificam significativamente a dificuldade de leitura. Destaquese, ainda, a existência de outros estilos de caligrafia nos cadernos, como a cursiva latina. Quando Nietzsche escreve textos em latim ou em línguas de origem romana, ele costuma recorrer à cursiva latina, ainda que isso não exclua inteiramente o uso desse estilo na sua escrita do alemão. Portanto, temos, pelo menos, quatro variações gráficas nos KN (Ver Fig. 1).

40 Cf. http://www.nietzschesource.org/DFGA/2 . Consultado em 23/11/2020. Importante apontar que a organização de Mette sofre correções quando incorporada à DFGA.

41 Cf. Carta a Heinrich Köselitz, 25 de janeiro de 1881, KGB III, 1.58. Cf. também: Carta a Franz Overbeck, 13 de julho de 1881, KGB III, 1.105.

42 Metterhausen já tinha assinalado que a caligrafia de Nietzsche no início desses documentos é bela e bem elaborada para logo se tornar variável e intricada, o que parece ser um reflexo das diferentes formas de tratamento conferidas: anotando rapidamente durante a aula ou reelaborando lentamente após a aula. Cf. Metterhausen, 1942, pp. $21-25$. 
Nasser, E.
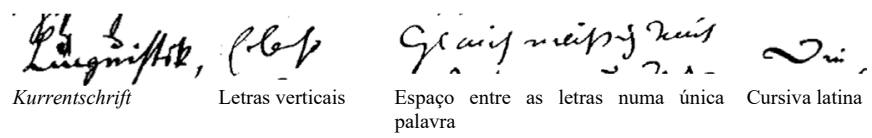

Fig. 1.

(ii) Um outro problema é que as anotações feitas por Nietzsche de diferentes cursos são frequentemente sobrepostas num mesmo caderno, sem uma clara separação ${ }^{43}$. Esse procedimento aparece pela primeira vez nas notas contidas no caderno C I 6 , tornando-se ulteriormente frequente. A identificação dessa colagem de anotações foi feita por Mette, que chama a atenção para a existência de notas de diferentes cursos agrupadas num mesmo caderno $^{44}$. A fim de explicitar esse procedimento, e as dificuldades decorrentes, tomemos aqui as anotações contidas na folha 61 do caderno C IV 4 (Ver Fig. 2). A partir da folha 54, inicia-se a primeira parte de anotações do curso de Ritschl, Die wichtigsten Lehren der lateinischen Grammatik (WS 1866-67), que se estende até a folha 61. Mas além das notas de aulas de Ritschl, encontramos nessa folha, na parte superior, o prosseguimento das anotações do curso de Konstantin von Tischendorf, Palaeographie (SS 1866), cuja primeira parcela de registros está localizada nas folhas 26 a - 53. Esse exemplo demonstra que uma parte significativa do conteúdo dos cadernos encontra-se distribuída de forma desordenada, uma característica que pode ocasionar equívocos. No caso descrito, o leitor poderia supor que o texto contido na folha 61 é, em sua integralidade, uma continuação das notas das aulas de Ritschl, pois não há nenhum tipo de indicação de uma mudança no que está sendo registrado. Além do mais, não há realmente um grande desvio temático que possa servir de alerta,

43 Metterhausen aponta essa característica como uma das grandes dificuldades que acompanha o trabalho com os KN. Cf. Metterhausen, 1942, p. 21.

44 Cf. Mette, 1994b, p. LV.

104 | Cad. Nietzsche, Guarulhos/Porto Seguro, v.42, n.1, p. 89-110, janeiro/abril, 2021. 
afinal, estava se discorrendo acerca da história do alfabeto latino desde a folha 58, na seção dedicada à doutrina dos elementos, tema não muito distante das discussões paleográficas, ao menos para o leitor não especializado.

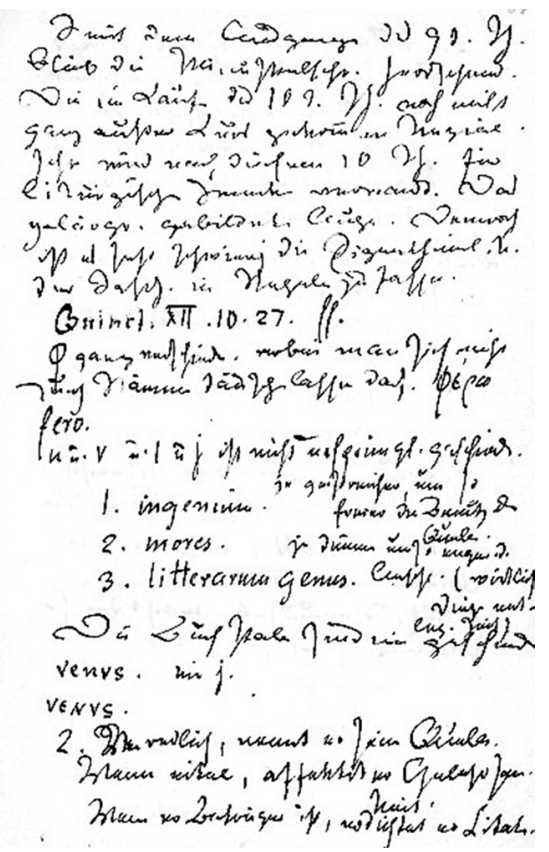

Fig. 2.

(iii) A existência de cadernos de notas que estavam em posse de Nietzsche, mas que não foram redigidos por ele. Esse é o caso do caderno C IV 3b, que possui notas do curso oferecido por Ritschl, Lateinische Grammatik (SS 1865). Embora Nietzsche tenha frequentado esse curso, ele não foi o autor das notas que temos à disposição na $\mathrm{DFGA}^{45}$.

45 Cf. Figl, 2007, p. 351

Cad. Nietzsche, Guarulhos/Porto Seguro, v.42, n.1, p. 89-110, janeiro/abril, 2021. | 105 
Nasser, E.

\section{Conclusão}

Vimos que a não publicação dos $\mathrm{KN}$ em sua integralidade na seção I da edição KGW foi prejudicial para as pesquisas sobre Nietzsche. Eu espero ter demonstrado que os cadernos universitários pertencem a uma classe especial de documentos que possuem não só valor para os estudos genéticos e de contextualização, como também - talvez principalmente - para os estudos de fontes. Embora não sejam exatamente notas de livros e de artigos, são registros escritos de um saber externo que posteriormente influenciará a produção própria de Nietzsche. Esse alargamento de significado faz com que os KN precisem ser tratados com maior seriedade, uma vez que o estudo de fontes é atualmente uma das principais tendências no âmbito da pesquisa Nietzsche.

Vimos também que, não obstante a edição DFGA ter iniciado a correção dessa lacuna da edição $\mathrm{KGW}$, publicando todos os cadernos estudantis de Nietzsche em formato fac-símile, o fato é que o conteúdo desse material não é ainda plenamente acessível. As restrições existentes só serão definitivamente ultrapassadas mediante a elaboração (i) de transcrições, (ii) de uma edição crítica dos manuscritos e, por fim, (iii) de um aparato crítico. 
Os Kollegnachschriften de Nietzsche. Considerações sobre uma lacuna...

\title{
Nietzsche's Kollegnachschriften. Considerations on a gap in the complete works
}

\begin{abstract}
Notwithstanding the renowned virtues of the critical edition - Kritische Gesamtausgabe (KGW) - it is known that the first two sections of this edition, comprising the youth and philological writings, have gaps. One of these gaps, contained in section I, comes from the troublesome decision of not incorporating, in its entirety, the class notes made by Nietzsche in the University period, the Kollegnachschriften, valuable both for genetic and contextualization studies, as well as for the study of sources. Even though the emergence of the Digitale Faksimile Gesamtausgabe (DFGA) has started to address this flaw by publishing all of Nietzsche's University notebooks in facsimile format, the problems of accessing these documents have not yet been completely overcome.
\end{abstract}

Keywords: Philology, Sources, Estate, Manuscripts.

\section{Referências}

ARENAS-DOLZ, F. Was ist eine Vorlesung bei Nietzsche? oder: Wie stellt Nietzsche den Text seiner Vorlesungen zusammen? Am Beispiel der „Einleitung in die Tragödie des Sophocles“ (SS 1870). In: Nietzsche-Studien 41, 2012.

. Also sprach Nietzsche. Zur Edition der Vorlesung „Einleitung in das Studium der klassischen Philologie“" (Sommersemester 1871). In : BORN, J. (Org.), Kolleghefte, Kollegnachschriften und Protokolle. Probleme und Aufgaben der philosophischen Edition, Berlin/Boston : Walter de Gruyter, 2019.

BENNE, C. Nietzsche und die historisch-kritische Philologie. Berlin/New York: Walter de Gruyter, 2005.

BORNMANN, F. Anedokta Nietzscheana aus dem philologischen Nachlass der Basler Jahre (1869-1878). In: BORSCHE, T., GERRATANA, F., VENTURELLI, A. (Org.), Centauren-Geburten'. Wissenschaft, Kunst und Philosophie beim jungen Nietzsche, Berlin/New York : Walter de Gruyter, 1994.

CAMPIONI, G. „Die Kunst, gut zu lesen“: Mazzino Montinari und das Handwerk des Philologen. In: Nietzsche-Studien 18, 1989.

COLSEN, M. The German Online Editions of Nietzsche's Works: A User's Perspective. In: The Journal of Nietzsche Studies 51, n. 1, 2020. 
Nasser, E.

D'IORIO, P. Die Schreib- und Gedankengänge des Wanderers. Eine digitalische genetische Nietzsche-Edition. In: Editio, 31, 2017.

DÄUBLE, H. Friedrich Nietzsche und Erwin Rohde: mit bisher ungedruckten Briefen in: Nietzsche-Studien, 5, 1976.

FIGL, J. Dialek der Gewalt. Nietzsches hermeneutisches Philosophie. Mit berücksichtigung unveröffentlicher Manuskripte. Düsserldorf: Patmos Verlag, 1984 .

. Die Buddhismus-Kenntnis des Jungen Nietzsche unter Heranziehung seiner unveröffentlichten Vorlesungsnachschrift der Philosophiegeschichte in: GÖSSMANN, E. ZOBEL, G. (Org.) Das Gold im Wachs. Festschrift fuir Thomas Immoos zum 70. Geburtstag. München: Iudicium Verlag, 1988.

. Nietzsches frühe Begegnung mit dem Denken Indiens: auf der Grundlage seiner unveröffentlichten Kollegnachschrift aus Philosophiegeschichte (1865). In: Nietzsche-Studien 18, 1989.

- Edition des frühen Nachlasses Friedrich Nietzsches: grundsätzliche Perspektiven. In: Nietzscheforschung 1, 1994.

. Die Abteilung I im Kontext der kritischen Gesamtausgabe der Werke Nietzsches. - In: Nietzsche-Studien 24, 1995.

. Vorwort. In: Kritische Gesamtausgabe I, Band 4. Berlin/New York: Walter de Gruyter, 1999.

. Nietzsche und die Religionen. Transkulturelle Perspektiven seines Bildungsund Denkweges. Berlin/New York: Walter de Gruyter, 2007.

FORNARI, M.C. Uma Aventura de mais de um Século. A História das Edições de Nietzsche. Trad. Maria Elisa Bifano. São Paulo: Editora Unifesp, 2019.

GERRATANA, F. e MÜLLER-BUCK, R. Nachbericht zur ersten Abteilung: Briefe von und an Friedrich Nietzsche Oktober 1849 - April 1869. Berlin/New York: Walter de Gruyter, 1993.

HOFFMANN, D.M. Zur Geschichte des Nietzsches-Archivs. Berlin/New York: Walter de Gruyter, 1991 . Das "Basler Nietzsche-Archiv". Katalog der Ausstellung. Basel, 1993.

HOLZER, E. Vorwort. In: Nietzsche’s Werke. Band XVII. Philologica. Leipzig: Alfred Kröner, 1910.

108 | Cad. Nietzsche, Guarulhos/Porto Seguro, v.42, n.1, p. 89-110, janeiro/abril, 2021. 
Os Kollegnachschriften de Nietzsche. Considerações sobre uma lacuna...

HOYER, T. Nietzsche und die Pädagogik. Werk, Biographie und Rezeption. Würzburg: Königshausen \& Neumann, 2002.

JANZ, C.P. Friedrich Nietzsche Biographie Band 1. München: Deutscher Taschenbuch Verlag, 1981.

MARTON, S. L'edizione Colli-Montinari e gli studi nietzscheani in Brasile. In: Il Ponte. Rivista di politica economia e cultura fondata da Piero Calamandrei 8/9, 2013.

METTE, H.J. Der Handschriftiliche Nachlass Friedrich Nietzsches. Leipzig: Verlag Richard Hadl, 1932.

. Vorwort zur Gesamtausgabe. In: Historisch-kritische Gesamtausgabe (BAW) I. München: C.H. Beck'sche Verlagsbuchhandlung, 1994a.

. Sachlicher Vorbericht zur Gesamtausgabe der Werke Friedrich Nietzsches. In: Historisch-kritische Gesamtausgabe (BAW) I. München: C.H. Beck'sche Verlagsbuchhandlung, 1994b.

METTERHAUSEN, W. Friedrich Nietzsche's Bonner Studentenzeit 1864/65. Murhard'sche Bibliothek der Stadt Kassel (prova tipográfica não publicada), 1942.

MONTINARI, M. Nietzsche Lesen. Berlin/New York: Walter de Gruyter, 1982.

MOST, G.; FRIES, T. <">: Die Quellen von Nietzsches Rhetorik-Vorlesung. In: Borsche, T., GERRATANA, F., VEnTURElli, A. (Org.), CentaurenGeburten'. Wissenschaft, Kunst und Philosophie beim jungen Nietzsche, Berlin/ New York : Walter de Gruyter, 1994.

NASSER, E. Nachweise aus Jacob Bernays, Joseph Justus Scaliger (1855). In: Nietzsche-Studien 49, 2020.

. Nachweise aus Gottfried Bernhardy, Grundriß der Römischen Litteratur (1865). In: Nietzsche-Studien 49, 2020.

. Nachweise aus Otto Jahn, Aus der Alterthumswissenschaft (1868). In: Nietzsche-Studien 49, 2020.

NIETZSCHE, F. Werke. Kritische Gesamtausgabe (KGW). Berlin/New York: Walter de Gruyter, 1969 - .

. Nietzsche Briefwechsel. Kritische Gesamtausgabe (KGB). Berlin/New York: Walter de Gruyter, 1975 - . 
Nasser, E.

. Sämtliche Briefe: Kritische Studienausgabe (KSB). Berlin/New York: Walter de Gruyter, 1986.

. Goethe-Schiller-Archiv (GSA) 71/43 Friedrich Ritschl, Institutiones grammaticae linguae latinae, SS 1865.

. Goethe-Schiller-Archiv (GSA) 71/53 Friedrich Ritschl, Einleitung und Anleitung zur lateinischen Grammatik, WS 1866/67.

. Goethe-Schiller-Archiv (GSA) 71/54 Friedrich Ritschl, Historische Grammatik der lateinische Sprache nebst Einleitung in die römische Epigraphik $\left({ }_{-}\right)$.

. Goethe-Schiller-Archiv (GSA) 71/55 Friedrich Ritschl, Lateinische Grammatik, WS 1866.

OVERBECK, F./ KÖSELITZ, H [Peter Gast]. Briefwechsel. HOFFMAN, D.M., PETER, N., SALFINGER, T. (Org.). Berlin/New York, 1998.

OVERBECK, F./ ROHDE, E. Briefwechsel. PATZER, A. (Org.). Berlin/New York, 1990.

PORTER, J. "Rare Impressions". Nietzsche's Philologica: A Review of the ColliMontinari Critical Edition. In: International Journal of the Classical Tradition 6, n. 3, 2000.

RIBBECK, O. Friedrich Wilhelm Ritschl: Ein Beitrag zur Geschichte der Philologie. Erster Band. Leipzig: B.G. Teubner, 1879.

ROSS, W. Der ängstliche Adler. Friedrich Nietzsches Leben. München: Kastell Verlag, 1997/98.

SANTINI, C. Die Methode der Quellenforschung am Beispiel der Basler Vorlesungen. In: Nietzscheforschung 19, 2012.

SCHLECHTA, K. Nachbericht zu den Philosophischen Notizen in: Historisch-kritische Gesamtausgabe (BAW) III. München: C.H. Beck'sche Verlagsbuchhandlung, 1994.

Enviado: 01/10/2020

Aceito: 05/11/2020

110 | Cad. Nietzsche, Guarulhos/Porto Seguro, v.42, n.1, p. 89-110, janeiro/abril, 2021. 